\title{
Modular simulation software development for liquid propellant rocket engines based on MATLAB Simulink
}

\author{
Mahyar Naderi ${ }^{1}$, Guozhu Liang ${ }^{2 a}$ and Hasan Karimi ${ }^{3}$ \\ ${ }^{1}$ Ph.d Candidate, School of Aeronautics and Astronautics, 100191 Beihang University, China \\ ${ }^{2}$ Professor, School of Aeronautics and Astronautics, 100191 Beihang University, China \\ ${ }^{3}$ Associate Professor, Faculty of Aerospace Engineering, K.T. University of Technology, Iran
}

\begin{abstract}
Focusing on Liquid Propellant Rocket Engine (LPRE) major components, a steady state modular simulation software has been established in MATLAB Simulink. For integrated system analysis, a new algorithm dependant on engine inlet mass flow rate and pressure is considered. Using the suggested algorithm, it is possible to evaluate engine component operation, similar to the known initial parameters during hot fire test of the engine on stand. As a case study, the reusable Space Shuttle Main Engine (SSME) has been selected and the simulation has been performed to predict engine's throttled operation at 109 percent of the nominal thrust value. For this purpose the engine actual flow diagram has been converted to 34 numerical modules and the engine has been modelled by solving a total of 101 steady state mathematic equations. The mean error of the simulation results is found to be less than $5 \%$ compared with the published SSME data. Using the presented idea and developed modules, it is possible to build up the numerical model and simulate other LPREs.
\end{abstract}

\section{Introduction}

In order to reduce the costs during design and enhancement phases, using software capable of precise modeling and simulating is favorable. For this purpose in this research a simulation tool is developed for steady state analysis of a RLPRE which can be further extended for simulating other types of LPREs.

In development of simulation software for LPRE analysis, many contributions have been done for example in 1995, C. Goertz suggested a modular method for static performance analysis of different LPRE cycles using Fortran (as it appears). [1]. In 2000, K. Liu, Y. Zhang developed a methodology for modularization modeling and transient simulation of LPREs and created an object oriented program using Microsoft Visual C++ 6.0 [2]. In 2009, C. R. Koppel et al.; used EcosimPro tool kit along with ESPSS libraries to implement and validate satellite propulsion systems modellings [3]. In 2011, F. D. Matteo and M. D. Rosa developed steady state library for ESPSS software for static simulation of liquid propellant engines [4]. In 2012, Y. Zheng et al. used the AMEsim software to simulate the dynamic behavior of unified spacecraft propulsion system [5]. In 2013, M. Naderi, A.R.Jalali et al. developed a GUI software for dynamic simulation of open cycle LPRE using FORTRAN 90 [6]. In 2015, L. Wei et al. used Modelica to establish componenet model libraries for LPRE [7]. As it is visible, by the evolution of computers, the researchers are tending towards

\footnotetext{
${ }^{a}$ Guozhu Liang : lgz@buaa.edu.cn
} 
developing more general softwares similar to toolkits. In the current research in order to analyze different types of LPRE cycle performance, a modular simulation software has been developed for steady state analysis, using MATLAB Simulink. Here MATLAB is chosen due to its high accessibility, applicability, simple programming language, convinient usage, rich library and toolboxes for different mathematical solution methods and finally ease of operation for future researchers to enhance the current software. Despite some of the previous literatures, the presented algorithm uses engine inlet mass flowrate and pressure as the system input, similar to the known initial conditions during hot fire test. For case study, SSME, as one of the most complicated, successful and comprehensive LPRE built up to now, is simulated and the results are compared with published data.

\section{Realization approach for modular simulation of LPRE}

The process of modular simulation is classified into five major steps: 1) Developing modular models for LPRE main components (here in MATLAB Simulink); 2) Validating the modules; 3) Establishing the desired LPRE numerical flow model from the actual flow diagram; 4) Developing an algorithm for determining the sequential solution order and method, based on module's input/output data; 5) Establishing the integrated model.

Reviewing the major elements for different types LPRE cycles, it is found that LPREs are generally constructed of seven major modules. These include connecting pipes, combustion chamber, nozzle, pre-burner (gas generator), pumps, turbines and controling valves. In this paper the cooling jacket is also considered as a module therefor a total of eight madules have been considered (Table 1). Some of these modules can also be connected to form a subsystem such as turbo-pump assembly or thrust chamber. With modular form of simulation, it possible to use the same modules for other LPREs containing similar componenets. Here the modules are constructed of linear/nonlinear lamped parameter steady state equations. Despite frequently used algorithms for steady state analysis [8-10], the chamber or pre-burner pressure is not known, but itself is a parameter required to be simulated. For this pupose an algorithm is developed which is based on the known parameters at main feed line enterance (i.e. oxidizer and fuel mass flow and pressure at engine inlet), similar to the case of testing the engine on test stand. The solution method is based on Newton Raphson iterative loops. For interpolating between the required inputs, the shape-preserving piecewise cubic interpolation method was used as Matlab function and showed good accuracy.

Table 1. Main modules in LPRE flow diagram

\begin{tabular}{|c|c|c|c|c|c|c|c|c|c|c|}
\hline \multirow{2}{*}{$\begin{array}{l}\text { Mode } \\
\text { Subsystem }\end{array}$} & & 基 & 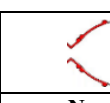 & 望 & III & 5 & 0 & 8 & 3 & \\
\hline & & $\mathbf{J}$ & zzle $^{\text {No }}$ & ipe & & ${ }_{\mathrm{mp}}{ }^{\mathrm{Pu}}$ & rbine $^{\mathrm{Tu}}$ & alve & & $\mathbf{T}$ \\
\hline
\end{tabular}

\section{Case study}

In this paper, SSME is selected as a case study. This engine is not only a SCCLPRE but also a RLPRE and is among one the most successful LPREs ever built. Furthermore, due to its special design, it has most of the complexities that all other engines might have, namely: using cryogenic propellant, separate turbo-pump assemblies on each propellant line, low and high pressure turbo-pumps, hydraulic turbine and etc. A detail description of SSME can be found in [11]. In order to model the engine, with regard to its actual flow diagram, a numerical model using the eight modules already discussed is prepared (Figure 1). The model is constructed of 34 modules as described in Table 1. Each module is based on steady state linear/nonlinear lumped parameter model mathematical equation. 

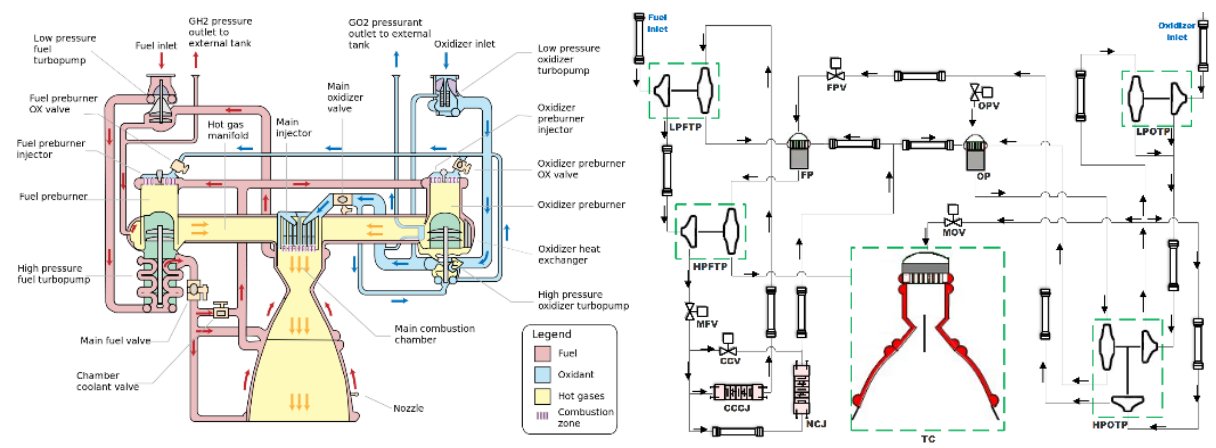

Figure 1. Comparison between SSME actual (left-[12]) and current simulated model flow diagram

The required input and produced output data for modules is described in Table 2 to Table 5 but due to page number limitations, only the modules on fuel line are mentioned.

The input variables are devided into three main catagories: Type "a" parameters: constant input values (e.g. LPFTP disk diameter) and in Figure 2 are depicted by pink color; Type "b" parameters: curves and graphs from which the desired value should be interpolated (e.g. combustion product gas temperature which is plotted versus propellant mixture ratio), depicted by orange color in Figure 2; Type "c" parameters: estimated in other blocks and will later be given to the current block as input (e.g. LPFTP pump outlet pressure is an input for HPFTP pump) depicted by cyan color in Figure 2.

Table 2. LPFTP turbo-pump input/output data

\begin{tabular}{|c|c|c|c|c|c|}
\hline \multirow{2}{*}{ LPTFP Turbine Parameter } & \multicolumn{2}{|c|}{$\mathbf{T}$} & \multirow{2}{*}{ LPFTP Pump Parameter } & \multicolumn{2}{|l|}{$\mathbf{T}$} \\
\hline & ype & at. & & ype & at. \\
\hline LPFTP Shaft Rotational Speed & put & c & $\begin{array}{l}\text { LPFTP Shaft Rotational } \\
\text { Speed }\end{array}$ & put In & \\
\hline CC Main Fuel Injector Pressure & put & c & $\begin{array}{l}\text { CC Main Fuel Injector } \\
\text { Pressure }\end{array}$ & put & \\
\hline CC Cooling Passage Pressure & put & c & Fuel Density & put & a \\
\hline Fuel Vapor Gas Constant & put & a & LPFTP Characteristic Map & put ${ }^{\text {In }}$ & b \\
\hline CC Cooling Passage heat ratio & put & c & LPFTP Pump Shaft Torque & $\begin{array}{r}\text { O } \\
\text { utput }\end{array}$ & - \\
\hline LPFTP Turbine Polytropic & It & & LPFTP Pump Input mass & O & \\
\hline $\begin{array}{l}\text { Efficiency } \\
\text { CC Cooling Passage }\end{array}$ & put & & flow rate & utput & \\
\hline Temperature & put & a) & & & \\
\hline LPFTP Characteristic Map & put & $b$ & & & \\
\hline LPFTP Turbine Shaft Torque & $\begin{array}{r}\mathrm{O} \\
\text { utput }\end{array}$ & - & & & \\
\hline LPFTP Turbine mass flow rate & $\begin{array}{r}\mathrm{O} \\
\text { utput }\end{array}$ & - & & & \\
\hline
\end{tabular}

Table 3. MFV and CCV input/output data

\begin{tabular}{|c|c|c|c|c|c|c|}
\hline \multirow[t]{2}{*}{ MFV Parameter } & T & C & \multirow{2}{*}{ CCV Parameter } & \multicolumn{3}{|l|}{$\mathbf{T}$} \\
\hline & уре & at. & & ype & at. & \\
\hline $\begin{array}{l}\text { HPFTP Pump Discharge } \\
\text { Pressure }\end{array}$ & nut & & MFV Discharge Pressure & In & & c \\
\hline $\begin{array}{l}\text { HPFTP Pump Discharge mass } \\
\text { flow }\end{array}$ & put & c & 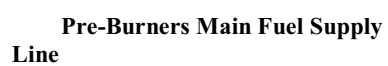 & put In & & c \\
\hline $\begin{array}{l}\text { MFV Nominal Area Ratio } \\
\text { Graph }\end{array}$ & put & $\mathrm{b}$ & $\begin{array}{l}\text { CCV Nominal Area Ratio } \\
\text { Graph }\end{array}$ & put & & b \\
\hline MFV Throttle Situation & put & a & CCV Throttle Situation & put & & a \\
\hline MFV Discharge Pressure & utput & - & CCV Discharge mass fllow rate & $\begin{array}{r}\text { O } \\
\text { utput }\end{array}$ & & - \\
\hline
\end{tabular}


Table 4. Fuel pre-burner and combustion chamber input/output data

\begin{tabular}{|c|c|c|c|c|c|c|}
\hline \multirow{2}{*}{ Fuel Pre-Burner Parameter } & \multicolumn{2}{|c|}{$T$} & \multirow{2}{*}{$\begin{array}{l}\text { Combustion Chamber } \\
\text { Parameter }\end{array}$} & \multicolumn{2}{|c|}{$\mathbf{T}$} & $\mathbf{C}$ \\
\hline & ype & at. & & ype & at. & \\
\hline Fuel Pre-Burner Fuel mass flow rate & put & c & MOV mass flow rate & put & & c \\
\hline Fuel Pre-Burner Oxid mass flow rate & put & c & rate $\mathrm{CC} \mathrm{Fuel} \mathrm{Injector} \mathrm{mass} \mathrm{flow}$ & put & & c \\
\hline $\begin{array}{l}\text { Nozzle Cooling Passage Temperature } \\
\text { inlet }\end{array}$ & put & c & HPOTP Boost Pump mass flow & put & & c \\
\hline Nozzle Cooling Passage mass flow & put & c & HPFTP Pump mass flow & put & & c \\
\hline Nozzle Cooling Passage Temperature & put & a & $\begin{array}{l}\text { CC Temperature-Mixture } \\
\text { Ratio Graph }\end{array}$ & put & & b \\
\hline $\mathrm{CCV}$ mass flow rate & put & c & $\begin{array}{l}\text { Product gama-Mixture Ratio } \\
\text { Graph }\end{array}$ & put & & b \\
\hline Fuel Pre-Burner Throat Diameter & put & a & $\begin{array}{l}\text { Gas Constant-Mixture Ratio } \\
\text { Graph }\end{array}$ & put & & b \\
\hline $\begin{array}{l}\text { Pre-Burner Temperature-Mixure } \\
\text { Ratio }\end{array}$ & put & $\mathrm{b}$ & $\begin{array}{l}\text { Combustion Chamber Throat } \\
\text { Area }\end{array}$ & put & & a \\
\hline Fuel Pre-Burner Pressure & $\begin{array}{r}\mathrm{C} \\
\text { utput }\end{array}$ & - & Combustion Chamber Pressure & $\begin{array}{r}\text { O } \\
\text { utput }\end{array}$ & & - \\
\hline Fuel Pre-Burner Temperature & $\begin{array}{r}\text { C } \\
\text { utput }\end{array}$ & - & $\begin{array}{l}\text { Combustion Chamber } \\
\text { Temperature }\end{array}$ & $\begin{array}{r}\text { O } \\
\text { utput }\end{array}$ & & - \\
\hline
\end{tabular}

Table 5. Nozzle cooling jacket and FP fuel line Inlet input/output data

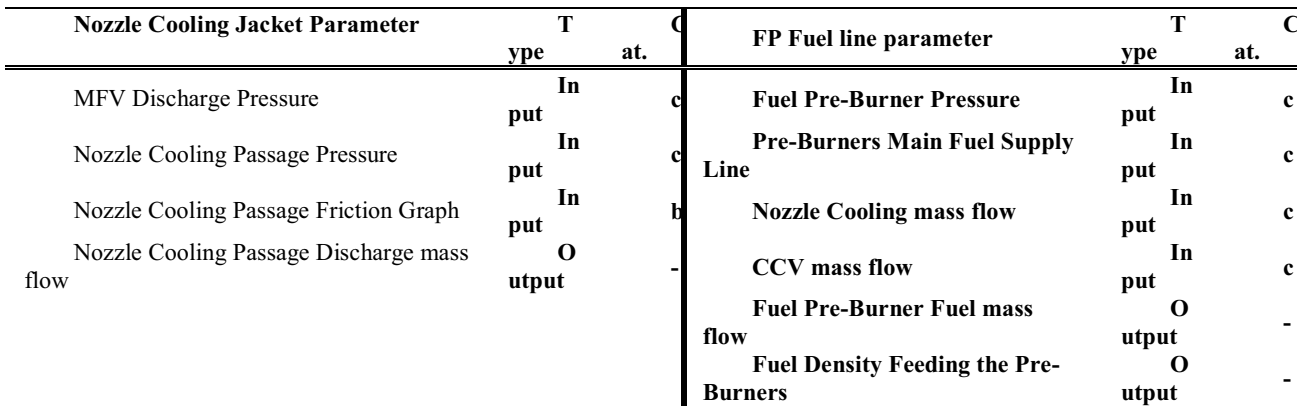

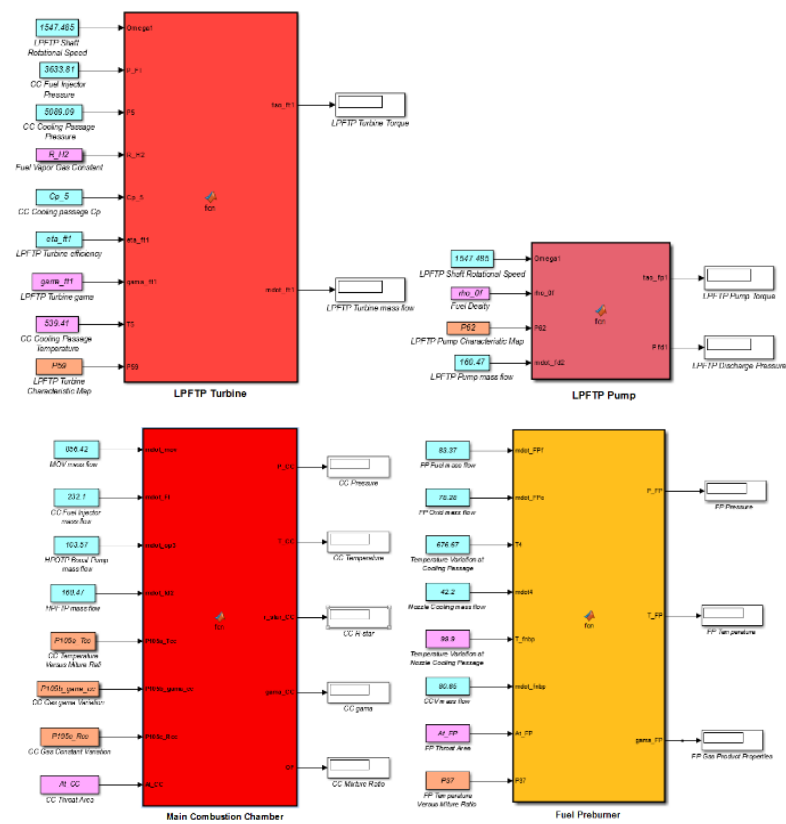


Figure 2. LPFTP turbine, pump, fuel pre-burner and combustion chamber Simulink module

After each module is verified, in order to form the integrated system model, the modules should be linked together with a correct logic according to the desired engine flow diagram (Figure 3).

Using given input data and nine initial guesses, the equations are solved by Newton Raphson iteration method. By correct connection of modules, an integrated model based on desired flow diagram can be formed. Considering SSME as our case study, the outer layer of the integrated Simulink model is shown in Figure 4.

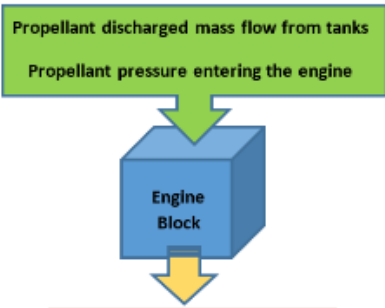

Calculate engine performance

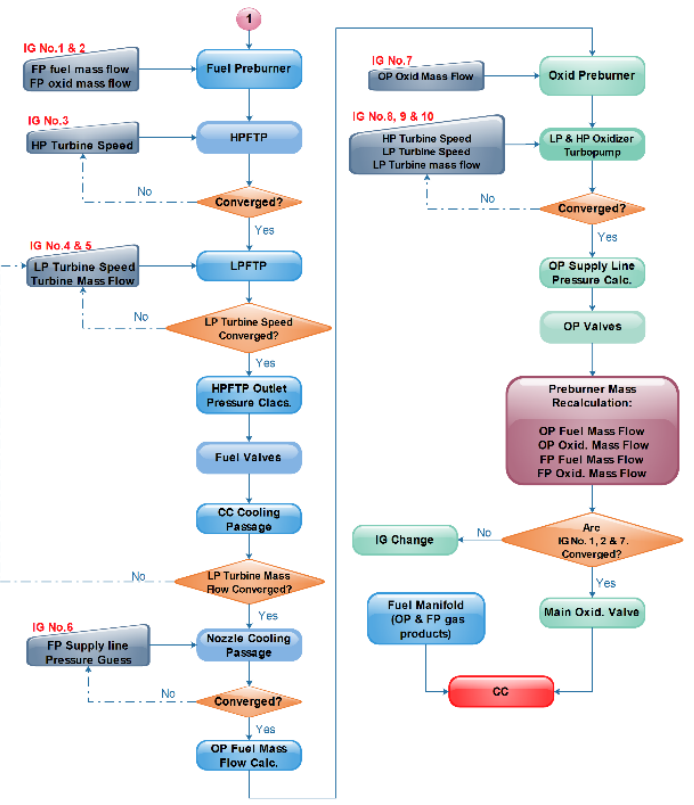

Figure 3. System simulation block diagram (left); SSME simulation algorithm (right)
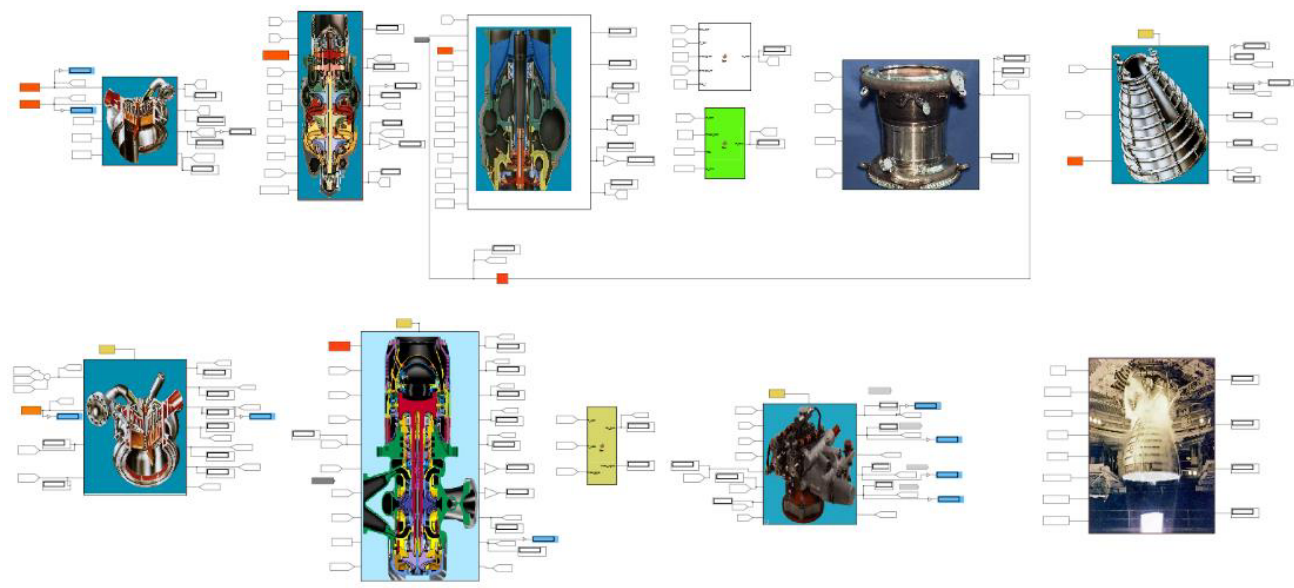

Figure 4. SSME integrated Simulink system simulation 


\section{Results}

For validating the suggested algorithm and simulation software, SSME RLPRE data throttled at 109 percent of nominal operation condition is used from Rocketdyne report [13]. For this purpose using the suggested algorithm in Figure 3, the integrated model of the engine (containing 34 modules) is formed in MATLAB Simulink. The total system of equations consisting of 101 linear/nonlinear equations are solved with Newton Raphson method. The required system level input values can be found in Table 6.

Table 6. SSME System input parameters at $109 \%$ thrust level

\begin{tabular}{|c|c|}
\hline Input Parameter & Value \\
\hline Fuel tank discharge mass flow & $\mathbf{7 2 . 7 9}^{\mathrm{kg} / \mathrm{s}}$ \\
\hline Oxidizer tank discharge mass flow & $\mathbf{4 3 6 . 7 2} \mathrm{kg} / \mathrm{s}$ \\
\hline $\begin{array}{c}\text { Absolute pressure at the end of the fuel } \\
\text { tank }\end{array}$ & $\mathbf{2 . 0 4}^{\mathrm{atm}}$ \\
\hline $\begin{array}{c}\text { Absolute pressure at the end of the } \\
\text { oxidizer }\end{array}$ & $\mathbf{6 . 8}^{\mathrm{atm}}$ \\
\hline
\end{tabular}

The simulation results can be found at Table 7. As it can be seen from the results, the governing equations used for turbo-pump system has leaded to fairly good accuracy except for the LPFTP wahich was in lack of initial data. The outlet pressure which is of course quiet dependable on the pump performance has been affected by the torque and speed, and the results seem to be following the expected trend. The turbine mass flow rate analysis shows great convergence and the results are satisfactory. The pre-burner pressure are precise which confirm the usage of the introduced equation sets for this element. For the combustion chamber, using CEA software for computing the gas product thermodynamic properties, the results do not show good precision but using the suggested equation for computing the gas properties from [13], the simulation results for this element are far better.

Table 7. Comparing simulation results

\begin{tabular}{|c|c|c|c|c|}
\hline \multicolumn{2}{|c|}{ Parameter } & Simulation & Rocketdyne [13] & Error \% \\
\hline \multirow{4}{*}{$\begin{array}{c}\text { Shaft } \\
\text { rotational } \\
\text { speed, } \Omega \\
(\mathrm{rpm})\end{array}$} & HPFTP & 36954.02 & 37354.67 & -1.07 \\
\hline & HPOTP & 31497.53 & 31133.36 & 1.17 \\
\hline & LPFTP & 15235.47 & 15806.83 & -3.61 \\
\hline & LPOTP & 5505.54 & 5447.11 & 1.07 \\
\hline \multirow{5}{*}{$\begin{array}{c}\text { Torque, } \tau \\
\text { (N.m) }\end{array}$} & HPFTP & 14389.05 & 14594.05 & -1.40 \\
\hline & HPOTP & 6489.89 & 6350.64 & 2.19 \\
\hline & HPOBTP & 449.72 & 438.58 & 2.54 \\
\hline & LPFTP & 1238.39 & 1327.43 & -6.71 \\
\hline & LPOTP & 2305.37 & 2271.32 & 1.50 \\
\hline \multirow{5}{*}{$\begin{array}{l}\text { Pump outlet } \\
\text { pressure } \\
\text { (atm) }\end{array}$} & HPFTP & 463.92 & 476.61 & -2.66 \\
\hline & HРOTP & 361.1 & 350.62 & 2.99 \\
\hline & HPOBTP & 590.79 & 573.95 & 2.93 \\
\hline & LPFTP & 16.05 & 17.63 & -8.96 \\
\hline & LPOTP & 30.82 & 30.10 & 2.39 \\
\hline \multirow{4}{*}{$\begin{array}{c}\text { Turbine } \\
\text { mass flow } \\
\text { rate, } \dot{m}_{t} \\
(\mathrm{~kg} / \mathrm{s})\end{array}$} & HPFTP & 72.79 & 73.32 & -0.72 \\
\hline & HPOTP & 30.01 & 28.61 & 4.89 \\
\hline & LPFTP & 15.1 & 15.73 & -4.01 \\
\hline & LPOTP & 79.35 & 78.73 & 0.79 \\
\hline \multirow{2}{*}{$\begin{array}{l}\text { PB pressure } \\
\text { (atm) }\end{array}$} & FP & 404.02 & 401.30 & 0.68 \\
\hline & OP & 401.96 & 399.30 & 0.67 \\
\hline \multirow{2}{*}{$\begin{array}{c}\text { CC pressure } \\
(\mathrm{atm})\end{array}$} & Exp. Gas prop. & 226.39 & 227.00 & -0.27 \\
\hline & CEA & 280.96 & 227.00 & 23.77 \\
\hline
\end{tabular}




\section{Conclusion}

A modular simulation software for steady state simulation of RLPRE was developed based on MATLAB Simulink. Eight general simulation modules for simulating engine main components was established. In the current simulation, despite commonly used algorithms, the simulation is not dependant on engine down stream parameters. As a case study, SSME as the most successful RLPRE ever built, was selected and the engine flow diagram was simplified and modularized to 34 component modules. A total of 101 linear/nonlinear equations were solved using Newton-Raphson iteration method. Comparing with the actual results for the engine's throttled operation at 109 percent of the nominal thrust value, it is concieved that the simulation has an acceptable average precision of more than 95 percent. As future work, the current precision can be enhanced by introducing more detailed initial data especially for the LPFTP assembley and the software can be further verified with other engine cycles.

\section{References}

[1] C. Goertz, "A modular method for the analysis of liquid rocket engine cycles," 1995.

[2] K. Liu and Y. Zhang, "A study on versatile simulation of liquid propellant rocket engine systems transients," 2000.

[3] J. M. C. R. Koppel, R. Perez , J. Steelant, P. Omaly, "A Platform Satellite Modelling With EcosimPro: Simulation Results," presented at the 45th AIAA/ASME/SAE/ASEE Joint Propulsion Conference \& Exhibit, Denver, Colorado, 2 - 5 August, 2009.

[4] F. Di Matteo and M. De Rosa, "Steady State Library for Liquid Rocket Engine Cycle Design," 2011.

[5] X. H. P. Z. Yan, Y. Q. Cheng, J. J. Wu, "System Dynamic Characteristic Simulation of Spacecraft Propulsion System Based on AMESim," Advanced Materials Research, vol. 605-607, pp. 679-683, 2013

[6] A. R. J. M. Naderi, H. karimi, "Modeling And Simulation Of Open Cycle Liquid Propellant Engines," Journal of Science and Engineering, vol. Vol. 1, 2013.

[7] C. L. L. Wei, X. Gang, D. Jing, Z. Haiming, Y. Hao, "Modeling and Simulation of Liquid Propellant Rocket Engine Transient Performance Using Modelica," presented at the Proceedings of the 11th International Modelica Conference, Versailles, France, September 21-23, 2015.

[8] M. Chitsaz, E. A. Tahmasebi, and H. Karimi M, "A Method for Simulation of a Cryogenic Liquid Propellant Engine," Applied Mechanics and Materials, vol. 110-116, pp. 2370-2376, 2011.

[9] D. H. H. Dieter K Huzel, Modern Engineering for Design of Liquid Propellant Rocket Engines. Washington DC, USA: American Institute of Aeronautics and Astronautics, 1992.

[10] H. L. Humble, Space Propulsion Analysis and Design USA: McGraw-Hill Inc., 2007

[11] "Space Shuttle Main Engine Orientation," in "BC98-04," Rocketdyne Propulsion and Power, BoeingJune 1998.

[12] (March, 2016). www.wikipedia.com.

[13] N. Dynamics, "SSME Model Dynamic Characteristics Related to POGO," Rocketdyne Division Rockwel International, 30th September, 1973.

\section{Abbreviation}

\begin{tabular}{|c|c|c|c|}
\hline $\mathbf{C C}$ & Combustion Chamber & LPRE & $\begin{array}{l}\text { Liquid Propellant Rocket } \\
\text { Engine }\end{array}$ \\
\hline $\mathrm{CCV}$ & Cooling Control Valve & MFV & Main Fuel Valve \\
\hline CJ & Cooling Jacket & MOV & Main Oxidizer Valve \\
\hline FP & Fuel Pre-Burner & OP & Oxidizer Pre-Burner \\
\hline FPV & Fuel Pre-Burner Valve & OPV & Oxidizer Pre-Burner Valve \\
\hline HPFTP & High Pressure Fuel Turbo-pump & PB & Pre-Burner \\
\hline НPOTP & $\begin{array}{l}\text { High Pressure Oxidizer Turbo- } \\
\text { Pump }\end{array}$ & RLPRE & $\begin{array}{l}\text { Reusable Liquid Propellant } \\
\text { Rocket Engine }\end{array}$ \\
\hline IG & Initial Guess & SCCLPRE & $\begin{array}{l}\text { Stage Combustion Cycle } \\
\text { LPRE }\end{array}$ \\
\hline LPFTP & Low Pressure Fuel Turbo-pump & TC & Thrust Chamber \\
\hline LPOTP & $\begin{array}{l}\text { Low Pressure Oxidizer Turbo- } \\
\text { Pump }\end{array}$ & & \\
\hline
\end{tabular}

